\title{
Elgin on understanding: How does it involve know-how, endorsement and factivity?
}

\author{
Emma C. Gordon ${ }^{1}$ iD
}

Received: 27 October 2018 / Accepted: 23 August 2019 / Published online: 18 September 2019

(c) The Author(s) 2019

\begin{abstract}
In Chapter 3 of True Enough, Elgin (2017) outlines her view of objectual understanding, focusing largely on its non-factive nature and the extent to which a certain kind of know-how is required for the "grasping" component of understanding. I will explore four central issues that feature in this chapter, concentrating on (1) the role of know-how, (2) the concept of endorsement, (3) Elgin's critique of the factivity constraint on understanding, and (4) how we might use aspects of Elgin's framework to inform related debates on the norm of assertion.
\end{abstract}

Keywords Elgin $\cdot$ Knowledge $\cdot$ Understanding $\cdot$ Know-how $\cdot$ Assertion

\section{Introduction}

True Enough is a rich, stimulating book, in which one of Elgin's central concerns is to argue that epistemologists should focus on understanding rather than knowledge-especially objectual understanding (i.e., understanding of a subject matter). She thinks that this is necessary in order to "accommodate the fruits of science and other systematic inquiry" (2017, p. 3), and we have good reasons to endorse Elgin's general suggestion of shifting focus towards understanding. One such reason is that understanding plausibly has an epistemic value that (propositional) knowledge lacks - for example, Pritchard (2012) and others (e.g., Greco 2010; Riggs 2008) claim that understanding, rather than propositional knowledge, is an achievement, a kind of success that is primarily creditable to ability. That said, there are some details of Elgin's discussion of that I believe require further development, and it is these rather than the points of agreement that will be the central focus.

For the purposes of this paper, my focus will be on Chapter 3, "From Knowledge to Understanding", which is perhaps the most interesting chapter from the point of

Emma C. Gordon

emma.catherine.gordon@googlemail.com

1 University of Edinburgh, Room 5.04, Dugald Steward Building, 3 Charles St. Lane,

Edinburgh EH8 9AD, UK 
view of mainstream epistemology (other chapters will be of special interest to, along with epistemologists, philosophers of science). In this chapter, Elgin begins to outline her account of understanding and explores the distinction between knowledge and understanding, in part by considering the sense in which understanding requires a grasping component (which, she thinks, requires a certain type of know-how which is not reducible to know-that). Crucially, Elgin also argues that understanding is, while not "indifferent to the facts", nevertheless non-factive-that one can understand even if one's account does not "consist exclusively or predominantly of truths" (2017, p. 33).

I will explore three central and interrelated issues about the nature of understanding that feature in this chapter and conclude by suggesting a novel application of the view. These concern (1) the role of know-how in Elgin's account of understanding and her treatment of Ryle's (1949) account of know-how (Sect. 2); (2) the role of endorsement in her account of understanding (Sect. 3); how to make a factivity constraint on understanding more plausible, and how doing so might influence Elgin's critique of factivity more broadly (Sect. 4); finally, Sect. 5 suggests a way to extend parts of Elgin's framework in order to advance debates about the norm of assertion.

\section{Know-how}

There is much to recommend Elgin's view that understanding essentially involves know-how. In addition, for present purposes I will accept Elgin's more general view that know-how is fundamentally dispositional [rather than propositional, as intellectualists like Stanley and Williamson (2001) maintain ${ }^{1}$ ]. Accordingly then, Elgin's view that understanding essentially involves know-how is best understood as a view that understanding involves a certain kind of disposition or dispositions-a position that already differentiates her proposal from reductivism about understanding, proponents of which hold that understanding simply reduces to propositional knowledge (e.g., Sliwa 2015; Kelp 2015, 2017)

The idea that understanding involves know-how, understood as a disposition, is not new; Hills (2009) for example advances this kind of proposal specifically in the case of understanding-why, and Duncan Pritchard in places comes close to holding such a view (e.g. 2016). Interestingly, though, Elgin is careful to distinguish between two ways in which we might theorize about understanding in terms of know-how, within the camp of those who reject that know-how is propositional (and accept that it is dispositional).

On the one hand, we might think that the kind of know-how that features in understanding is essentially dispositional, viz., that the relevant know-how just is some suitably specified disposition. For ease of reference, call this view strong dispositionalism. This is the view of know-how that Elgin attributes to Gilbert Ryle.

\footnotetext{
1 According to Stanley and Williamson (2001), and more recently Stanley (2011), one knows how to do something $\mathrm{X}$ if and only if (roughly) there is a way for one to $\mathrm{X}$, $\mathrm{w}$, and one knows that $\mathrm{w}$ is a way for one to X. The alternative that Elgin refers to as dispositionalism owes initially to Ryle $(1945,1949)$.
} 
Strong dispositionalism can be distinguished from weak dispositionalism-the denial of the view that know-how just is propositional knowledge, in conjunction with the claim that possessing know-how in some sense involves disposition.

In challenging the kind of strong dispositionalism she attributes to Ryle, Elgin writes:

Knowing-how is not a mere multi-track disposition. Knowing how is an achievement. It involves a capacity to do something well, or rightly, or correctly. An adequate explanation should do justice to this normative character [...] What's missing from Ryle's account is the normative element (2017, p. 48).

This passage is an interesting one, and if Elgin's right, then her line of reasoning here has implications not only for how we might think of understanding in terms of know-how, but also for the vexed issue of how we should best articulate the dispositionalist (alternatively, 'anti-intellectualist') alternative to propositionalism within the theory of know-how.

Let's focus first on Elgin's observation that know-how is an achievement, viz., minimally, a kind of creditable success. ${ }^{2}$ Prima facie, it seems that Elgin is quite right that knowing how is an achievement. That said, there is a sense (I'll shortly clarify) in which the Rylean view that knowledge-how is a disposition (i.e., an ability) could potentially accommodate this point. And if that's right, then the observation that know-how is an achievement needn't lead us to part ways with Ryle's identification of know-how with a certain kind of disposition.

Here it will be helpful to take as a starting point Bengson and Moffett's (2011) point that any account of know how should distinguish between two different ways know-how relates to intelligent action, by:

1. Being in a state of knowing how; e.g., as when one knows how to do a triple lutz jump, while one is lying comfortably in bed. Here, the know-how is not manifested in action, even if one has all the right dispositions to do so if one tried.

2. Exercising knowing-how; as when one manifests one's state of know how in action, i.e., as when one skilfully performs a triple lutz.

Knowing-how in the second sense is surely an achievement (for example, a triple lutz that manifests a skater's know-how is an achievement even if simply making all the moves of the triple lutz by guesswork and luck is not); and this is because knowing how in the second sense is a kind of success because of ability. However, it's less initially obvious that merely being in a state of knowing how is an achievement. ${ }^{3}$ It may be-perhaps being in that state (whereby one has the relevant disposition) is

\footnotetext{
${ }^{2}$ For a highly influential account of achievement in mainstream epistemology, see Greco (2010). On Greco's view, achievements are essentially successes because of ability. See, however, Bradford (2015) for a more demanding account of achievement, according to which achievements involve difficulty and/or the overcoming of obstacles.

${ }^{3}$ For a defence of the view that know-how is a cognitive achievement, see Carter and Pritchard (2015).
} 
itself a success because of other abilities ${ }^{4}$ — but the most natural sense to grant that know-how is an achievement is in the second sense-exercising know-how. That's where the intuition is surely strongest.

With the foregoing points in mind, the proponent of a Rylean strong dispositionalist view of know-how (on which know-how = multi-track dispositions) can at this point respond along the following lines: (1) know-how is an achievement, granted, when one manifests one's know-how in action. (2) But since it's less obvious that merely being in a state of know how is an achievement than that manifesting knowhow is an achievement, it's no obvious problem for strong dispositionalism that what the view identities with being in a state of know how involves isn't an achievement. (3) Therefore, and contrary to Elgin's suggestion, the observation that knowledgehow is an achievement shouldn't itself lead us to have to part ways with the standard Rylean account of know-how as a disposition.

There is, though, a second line of reply available to the Rylean against Elgin's argument from achievement against strong dispositionalism. The second line of reply takes issue with what Elgin takes to be a problematic implication for strong dispositionalism of the insight that know-how is an achievement—viz., the implication that know-how involves a kind of normativity that strong dispositionalism can't account for. What I want to now suggest is that there is scope to make sense of the normativity of know-how if you are a strong dispositionalist who says that (being in a state of) knowing how just is possessing a disposition.

Such a strategy would proceed as follows. ${ }^{5}$ Firstly, the strong dispositionalist could identify know-how with a specific kind of disposition: what Sosa calls a competence (e.g., 2010, 2015, 2017). Secondly, they could insist that because competences are essentially normative, it follows that even if the view that know-how involves achievement preserves the datum that know-how is normative, so likewise does at least one way of defending the strong dispositionalist's identification of know-how with dispositions.

Why are competences essentially normative? The answer can be appreciated by considering two kinds of dispositions to succeed at doing something when one tries. Suppose that (due to many strangely spent hours practicing in Antarctica) I am disposed to keep the car on the road perfectly whenever-and only when-I drive on a solid block of ice; however, whenever I drive on a normal (i.e., dry) road, I am disposed to swerve dangerously. Do I have what we'd normally recognize as a competence to drive a car, even though I can't drive successfully on normal roads, simply because I can drive successfully on slick roads? On Sosa's view, I do not. And this is because what counts as the competence to drive a car is defined as a disposition to succeed reliably enough not just any old way, but when in proper shape and properly situated.

\footnotetext{
${ }^{4}$ For example, we might imagine that when one is in the state of knowing how to count cards in a game of blackjack, the being in this state is a success even if one doesn't go on to count cards, simply because one reached this state (i.e., a success) through the exercise of abilities (e.g., the abilities to do the relevant maths, which one employed when learning to count cards).

${ }^{5}$ Variations on this strategy have been suggested by Lowenstein (2017), and separately, by Carter and Navarro (2017).
} 
What makes the competence to drive a car a disposition to do so on legal roads and such, rather than on a block of ice, is that those conditions (and not the block of ice conditions) are the conditions that society values good performance in (Sosa 2017). It is in this respect that competences are essentially normative. And so if being in a state of know-how was just a matter of possessing a Sosa-style competence, then it would not be devoid of normativity. Here is not the place to attempt to defend this proposal further; rather, the claim is (more weakly) the following: if as Elgin tells us, understanding essentially involves know-how, then it's not ultimately clear why the kind of know-how understanding involves couldn't be unpacked just as Ryle has unpacked it. At least, the considerations Elgin appeals to about achievement and normativity aren't under closer inspection decisive reasons to part ways with Ryle.

At this point it is worth registering an important sense in which the kind of Sosastyle unpacking of Ryle's view not only avoids the normativity-based objection that Elgin takes Ryle's view to face, but that it actually better explains know-how's normativity than her own explanation does. On Elgin's view, the normativity of knowhow is importantly tied to rule following. As she puts it, 'much know-how seems to be a matter of following the rules of a practice. And it is plausible that the knowhow required for epistemic acceptance is practice based' (2017, p. 49). Quite rightly, Elgin rejects the idea that this rule following requires that one 'intentionally regulate one's behavior by reference to the rule' (ibid. 49). However, she also rejects any extreme alternative according to which know-how amounts to blind rule following, in the sense of 'automatically, unthinkingly behaving in accord with the norms of a practice' (ibid. 50). In an effort to find a middle ground between these extremes, Elgin opts for the following idea: that the normativity of know-how is a matter of one's acting on account of a rule as opposed to merely acting in accordance with a rule. In order to illustrate this difference, she offers the following case:

RED LIGHT: Except in New York City, drivers in the United States are permitted to turn right at a red light unless a sign saying 'No Turn on Red' is posted at the intersection. In New York City, right turns on red are never permitted. Drivers from out of town tend to be unaware that New York is an exception to the general rule. Suppose Meg, a denizen of a small town in Kansas, is driving in New York. Unsurprisingly, she finds the experience harrowing. She stops at every red light, not because she is aware of or sensitive to the law, but because she considers New York drivers and pedestrians reckless and wildly unpredictable. She deems it safer to proceed only when the light is green. She acts in accord with the law, but not on account of it. The regularity in her behavior is not an instance of following the traffic law. Although it may be an instance of knowing how to drive safely, it is not an instance of knowing how to obey New York traffic laws. Acting in accord with the law is not the same as acting on account of the law (see Kant 1981). And only acting on account of the law qualifies as knowing how (ibid. 50).

If exercising know-how is a matter of acting not merely in accord with some rule or standard, but acting on account of that standard, then exercising know-how involves neither intentional rule following (which is implausible, given that often 
know-how is manifested second-nature) nor blind or accidental rule-following. And this looks to be a pleasing outcome.

The fly in the ointment, however-and here is the fundamental problem with locating the normativity of know-how in rule following of any kind-concerns the kind of know-how that is exhibited in cases of expertise. Consider, in particular, cases of expertise that involve novelties - e.g., performances that create new standards of success as opposed to conforming to existing success standards. A famous example of such a novelty involves Ulrich Salchow, a Swedish figure skater who in 1909 became the first to attempt a rotating jump (later termed, a 'Salchow' in a skating competition. Prior to 1909, the success standards in skating were formulated in a way that did not include reference to rotating jumps. After 1909, such jumps were commonplace and expected at top-level competition.

With reference to the Salchow case, it is plausible that Salchow manifested his skating know-how in performing his jump for the very first time, and more generally, that skilful novelties are know-how manifestations. This datum is looks very difficult to explain on the view that know how essentially involves performance on account of rules or success standards. In a case like Salchow, the jump was exceptional despite its deviation from normal standards of successful skating.

The kind of Sosa-style gloss on a simple Rylean account of know-how, by not locating the normativity of know-how in rule-following, avoids this problem. By way of reminder, on such a view, the normativity of know-how is explained not with reference to norm following; rather, the idea is that what counts as know-how apt abilities is itself explained by reference to performance conditions that are of value to us. Novelties are valuable performances (imagine cheers for Salchow's first jump) despite the fact that they are not performed on account of extant and accepted rules. Such cases accordingly seem to be better accounted for on the proposal offered than on the view Elgin has recommended.

\section{The endorsement thesis}

I want to turn now to some questions that I think are worth considering in connection with Elgin's view that understanding involves such attitudes as endorsement and commitment. For example, she writes "Understanding is an epistemic commitment to a comprehensive, systematically linked body of information ..." (2017, p. 44). Elsewhere, she says "Understanding on my view is a (perhaps tacit) endorsement ..." (2017, p. 45). For ease of reference, let's refer to this general idea as the endorsement thesis:

Endorsement Thesis: If a subject S understands a topic F, and S's understanding is constituted by the body of information $\mathrm{X}$, then $\mathrm{S}$ epistemically endorses $\mathrm{X}$.

Including in one's account of understanding something like Elgin's Endorsement Thesis offers an elegant way to get the right result in cases that look otherwise very much like understanding but where such endorsement is lacking. It will be helpful at this point to consider an analogy with knowledge and imagination. 
Suppose I imagine that the suspect is guilty-I picture this in my mind, by visualising the suspect committing the crime. Suppose further that I have evidence for thinking this true, but for whatever reason, I in no way commit myself epistemically, by belief or otherwise, to the proposition that the suspect is guilty; I simply imagine this in the absence of any such a commitment, as I might when taking myself to engage with fiction. In such a case, I surely don't know that the suspect is guilty (regardless of whether the suspect really is guilty); from my own point of view, I've merely engaged in 'make believe'.

Something similar surely goes for understanding. Just suppose that [to use a variation on a case by Riggs (2009)] you are confused by your friend's aquaphobia; you know your friend is very afraid of water, but you don't understand his fear of water. Suppose that, feeling uncomfortable with this confusion, you concoct an imaginative story about your friend's history and relationship with water, according to which the friend's parents had harshly punished the child for something while they were near water. Suppose further that you (in the sense Elgin demands) know how the relevant explanations between the various bits of this story you've concocted fit together and furthermore know how to draw relevant inferences from this imaginative and perfectly coherent picture you've concocted.

Let's now add to the story. Suppose you then come to gain evidence for thinking that things with your friend and his acquiring a fear a water happened just as you imagined they did. You might now understand your friend's aquaphobia. But, as the Endorsement Thesis seems to rightly imply, you did not count as understanding your friend's fear of water prior to having the kind of commitment or endorsement of the bits of the story you acquire later, viz., back when you lacked any such endorsement, having concocted the story through imagination.

Although cases like the aquaphobia case speak in favour of the Endorsement Thesis, there are however other cases where understanding is plausibly present even though there's a sense in which the relevant body of information is in no way endorsed or committed to (in fact, even when it is explicitly rejected).

To sharpen this point, it will be useful to take as a reference point a kind of 'understanding twist' on Jennifer Lackey's much-discussed 'Creationist Teacher' case (2008, p. 48).

CREATIONIST TEACHER (understanding variant) (CT-U): Stella is a devoutly Christian university professor, and her religious beliefs are grounded in a deep faith that she has had since she was a very young child. Part of this faith includes a belief in the truth of creationism and, accordingly, a belief in the falsity of evolutionary theory. Despite this, she fully recognizes that there is an overwhelming amount of scientific evidence against both of these beliefs. Stella, in fact, reads contemporary scientific journals and regularly teaches advanced graduate seminars on evolution, where students and colleagues alike admire the deep appreciation Stella has of how the theory holds together. Moreover, Stella readily admits that she is not basing her own commitment to creationism on evidence at all but, rather, on the personal faith that she has in an all-powerful Creator. 
In CT-U, there's a clear sense in which Stella does not endorse evolution; she does not believe the propositions that purport to characterise evolution-she positively thinks they are false. Moreover, Stella in CT-U is not epistemically committed to the view in so far as it is straightforwardly at odds with her creationist beliefs. That said, however, it is not obvious that Stella doesn't understand evolution. ${ }^{6}$ Though neither Stella nor our protagonist in the aquaphobia case satisfy the Endorsement Thesis's constraint, Stella is very much unlike the subject in the aquaphobia case prior to gaining the evidence she does. Crucially, Stella is engaging in more than mere fiction, from her own perspective, despite her explicitly disavowing by regarding as false the body of information characterising the evolutionary process. In this respect, then, it looks like Elgin's Endorsement Thesis is going to struggle with a certain class of case, which indicates the condition is too strong as stated as a condition on understanding.

One interesting, though I think ultimately unsuccessful, thread of resistance to this concern draws from Elgin's remarks on belief, conviction and acceptance (ibid. 19). Elgin writes that:

[t]he term 'belief' is ubiquitous in epistemology. To avoid (or at least minimize) confusion, I will use the term 'conviction' for what Cohen calls 'belief'. To be convinced that $\mathrm{p}$ is to be disposed, when attending to issues raised or items referred to by $p$, normally to feel that it is true that $p$ and false that $\sim p$. To accept that $\mathrm{p}$ involves being willing to take $\mathrm{p}$ as a premise, as a basis for action or, I add, as an epistemic norm or a rule of inference, when one's ends are cognitive. This includes being willing to give others to accept that $\mathrm{p}$ via testimony. Acceptance is not a disposition to represent, but a disposition to act (ibid. 19).

With reference to this distinction, it might be argued that Stella does endorse evolution in virtue of her acceptance, rather than in virtue of her belief. This suggestion sounds initially reasonable, though it is on closer inspection not clearly available to Elgin. To bring this point out, compare Stella with a non-creationist science teacher. The non-creationist science teacher not only (in Elgin's terms) is convinced by evolutionary theory, but they also accept it in the sense that they have the relevant disposition to act in accordance with the theory. Stella differs from the non-creationist science teacher in an important respect: her disposition to act is extremely contextually sensitive. We are to assume it is only in the classroom that the disposition manifests. We have no reason to suppose Stella continues to act as if the evolution is correct elsewhere-but rather, given her creationist convictions-the natural way of reading the case is one on which she'll act as if it's false the rest of the time. ${ }^{7}$

\footnotetext{
6 See, however, [REDACTED] for a different kind of diagnosis of this case.

7 Granted, even so, Stella acts as if evolution were true to a greater extent than someone who, say, never manifested this disposition, in the classroom or otherwise. This is the case simply because, for Stella, there is a context in which she acts as if it is true. Does this give us reason to think that Stella thereby accepts evolution in virtue of having a disposition (even if highly context-sensitive) to act as if it were true? Here I think an analogy to dispositions to believe will be helpful. We aren't inclined to attribution to someone, $\mathrm{S}$, a disposition to believe $\mathrm{X}$ even if there are some very specific contexts in which $\mathrm{S}$ would believe $\mathrm{S}$. For example, suppose someone is inclined to believe their mother loves them only when talk-
} 
Making this feature of the case salient casts doubt on the thought that Stella clearly satisfies the Endorsement Thesis even on a weakened version of it which trades on acceptance rather than belief.

An additional strategy for responding to the above thread of argument proceeds along the following lines: perhaps Stella's understanding is just of the doctrine of evolutionary theory but not of the "phenomena that the doctrine purports to be about" (e.g., as one who disbelieves astrology might understand that doctrine but not understand the phenomena it purports to be about, i.e., celestial causation). ${ }^{8}$ But even if we grant that Stella understands the doctrine in the way that one might understand a theory that's 'untethered' entirely from reality (like astrology), might not Stella be in a better position here? After all, her 'grasp' or tether here seems to be a well-founded one. It's not entirely clear from Elgin's own discussion of endorsement how a refinement of the Endorsement Thesis might work in order to address CT-U style cases, but it seems that some kind of refinement will ultimately be needed.

\section{Understanding, factivity and centrality}

In this section, I want to focus on the non-factivity component of Elgin's account of understanding, particularly by considering in some detail the kind of motivation one might have for moving away from (a plausibly stated version of) the more standard factive proposal, such as that defended by Kvanvig (2003) and which Elgin rejects.

It should be uncontroversial that one can understand a subject matter even if some of one's beliefs about that subject matter are false. In this sense, a 'super' factive conception of understanding is too restrictive. What's at issue between factive and non-factive proposals is accordingly not whether understanding tolerates some false beliefs, but rather, to what extent understanding tolerates false beliefs.

Elgin takes her opponent to be moderate factive accounts, viz., those with a formulated factivity constraint on understanding that applies only to some set of 'central' beliefs. A familiar way of capturing this idea, due to Kvanvig (2003), is that understanding a subject matter $\varphi$ requires true central $\varphi$-beliefs but is compatible with false peripheral $\varphi$-beliefs. Alternatively: a subject $S$ can have objectual understanding of subject matter $\varphi$ only if amongst S's central $\varphi$ beliefs there are no false beliefs.

Of course, restricting a factivity condition on understanding to central beliefs within a body of information is only going to be plausible if centrality can be articulated in a way that marks some meaningful difference between central and noncentral beliefs. If factive views cannot achieve this, then this is a serious theoretical

\section{Footnote 7 (continued)}

ing to their therapist. The intuition here would be to withhold attributing a flat-out disposition to believe. And, by parity of reasoning, a similar diagnosis looks plausible in the case of Stella. Neither Stella, nor our therapy subject, manifests the relevant disposition in normal conditions. Thanks to a referee at Synthese for suggesting development of this line of thinking.

8 Compare with Elgin (2017, p. 45). 
mark against such proposals (in contrast with non-factive accounts, which needn't make any such distinction).

In what follows, I want to do two main things in this section; first, I want to sketch how centrality might be best unpacked within a factive model of understanding, and in such a way as to save factive proposals from the style of objection just canvased; and then, I'll conclude the section by considering a separate and I think fruitful application of the notion of centrality (refined in the context of factive proposals) to Elgin's own non-factive view.

\subsection{Centrality and factivity}

On what basis should propositions count as 'central' to a subject matter (such that, if believed falsely, they will be capable of undermining what would otherwise count as understanding)? Just how, exactly, are central beliefs to be distinguished from peripheral beliefs, vis-à-vis some body of information? Unfortunately, factive views such as Kvanvig's have had little to say on this, relying mostly on aphorism and analogy.

Perhaps we can start by taking a cue here from Elgin herself, noting that a significant part of what we can do with understanding involves being able to (1) make predictions and (2) manipulate information based on that understanding. ${ }^{9}$ To a first approximation, then, we might try to answer the question of whether a belief is central or not by asking whether (or how much) that belief matters with respect to our ability to make predictions and manipulation information-viz., with what we do with understanding.

This idea-as a working insight—comports well with the idea that some beliefs don't matter much in this respect. For example, believing falsely that the Socialist realism art movement in Russia began in 1931 rather than 1932 would not significantly undermine your reliability when making predictions or manipulating information with respect to the subject matter of modern Russian history. If - as the current working idea goes - a belief's being central is a matter of how much having (or not having) that belief would affect your reliability in predicting/manipulating information on the subject matter, then such a belief isn't central to your understanding of modern Russian history. And so, a plausibly formulated factive account of understanding-one that says that one can't have false central beliefs — could with reference to this explanation say in a principled way why understanding is compatible with beliefs like this one.

By contrast to the previous case, believing some things falsely (within a given subject matter) actually would plausibly significantly undermine your reliability when making predictions or manipulating information about that subject matter. Such beliefs are in this respect practically relevant to your understanding. What this all suggests, initially, is that-insofar as we want to say something illuminating

\footnotetext{
${ }^{9}$ See, e.g., Elgin (2017, p. 44).
} 
about what makes a belief central, we should do so along the following lines-by understanding centrality in terms of practical relevance as follows:

Practical Relevance: S's belief B is (highly) practically relevant to S's objectual understanding, $\varphi=$ Df. $S$ believes $B$, and were $S$ to believe falsely whether $B$, this would significantly undermine $S$ 's reliability when $S$ makes predictions or manipulates information with respect to subject matter $\varphi$.

Centrality: S's belief B is central to S's objectual understanding, $\varphi=$ Df. B is highly practically relevant to S's understanding of $\varphi$.

Now, if central beliefs are the highly practically relevant beliefs (as per above), and if highly practically relevant beliefs are ones that significantly influence what one can do with one's understanding, ${ }^{10}$ then we might press further and ask: What makes a belief capable of having this influence in the first place? What would make a given belief (if false) sabotage one's reliability in prediction and manipulation of the subject matter?

Here is a plausible line of thought in response to these questions: All things equal, the greater the number of $\varphi$-beliefs that directly 'depend upon' a given belief B for $S$, the more influence $B$ will have over what $S$ can do (practically speaking) with the putative $\varphi$-understanding (vis-à-vis prediction/manipulation). Consider, for example, the following. Suppose you come to find out that a family member-Abel -incarcerated for many years for committing a series of grisly murders - is actually innocent (despite having pled guilty and convinced everyone he was). By learning this, you'd be inclined to revise or give up a lot of beliefs you previously had about Abel, his character, his dispositions, his reasons for doing certain things, etc.

Given that a lot of beliefs you have about Abel depend in this way on your belief that he is a murderer (beliefs you would give up upon learning he is not), that belief is an influential one within the body of information that forms the (putative)

\footnotetext{
${ }^{10}$ It is worth noting a caveat to the above account of practical relevance. Suppose, for example, B is such that, were $\mathrm{S}$ to believe falsely whether $\mathrm{B}$, this would significantly undermine S's reliability when $\mathrm{S}$ makes predictions or manipulates information with respect to subject matter $\varphi$; but, suppose further that the kind of predictions or information manipulations that $S$ happens to be inclined to use $\varphi$ with respect to are highly abnormal, or that they otherwise reflect idiosyncratic desires. For instance, imagine that S's understanding of higher maths is such that $\mathrm{S}$ uses such maths only to analyse, predict, and manipulate football statistics and for nothing else. One might press that, on the account of centrality framed in terms of practical relevance which I've offered, it looks as though, implausibly, such epistemically irrelevant desires will have an influence on what counts as central to understanding higher maths. One response to this point is to simply regard what's described here as an acceptable kind of pragmatic encroachment on understanding. I'm not inclined toward such a diagnosis. An alternative, which I take to be more plausible, involves further unpacking the condition so that it blocks such encroachment. For instance, we might qualify the view as follows: B is practically relevant (in the sense demanded for centrality) if it is such that, were $S$ to believe falsely whether B, this would significantly undermine S's reliability (1) when $S$ makes predictions or manipulates information with respect to subject matter $\varphi$; (2) were $S$ to make a suitably wide range of predictions or information manipulations with respect to subject matter $\varphi$, and regardless of whether one does in fact make such predictions, etc. Adding this second clause helps us to deal with cases like the football statistics case noted above. Of course, the proposed second clause would need to then be supplemented with a plausible formulation of 'suitably wide class', e.g., perhaps with reference to normalcy or safety. Thanks to a referee at Synthese for raising this point.
} 
understanding you have of Abel. Moreover, being wrong about this particular matter-viz., his guilt or innocence of the grisly murders-would significantly undermine your reliability when making predictions or manipulating information about him. Such a belief is thus, on the view suggested, (1) highly practically relevant to your understanding of your family member; and (2) therefore, central to that understanding.

A proposal along these lines can accommodate some intuitive results. Firstly, the centrality of a given belief is positively correlated what we use understanding to do. Secondly, it excludes from centrality beliefs that have little import to prediction/ manipulation; and those on which not much depends. Thirdly, it can explain, in a broadly similar way to Elgin's view, the (instrumental) epistemic value of understanding in terms of what one can do with it. In these respects, some of the initial motivations for moving away from a factive construal of understanding are vitiated.

\subsection{Centrality and non-factivity}

The foregoing strategy for unpacking a factive account such as Kvanvig's has shown us how we might flesh out the notion of centrality in order to help us determine which beliefs should plausibly qualify as central, and thus capable of undermining understanding if they are false. This provides what is perhaps a more charitable construction of the kind of factive proposal Elgin dismisses as implausible, one that also retains the spirit of a key aspect of Elgin's own proposal-specifically, the idea that central to understanding is the ability to use the body of information you understand.

That said, the account of centrality suggested in the service of formulating a (more charitable) factive view might also be of use to another element of Elgin's own proposal. To see this potential application, consider Elgin's remark that "We now can see that [sic. understanding] involves knowing how to wield the commitments that bear on the topic-how to draw the inferences and perform the actions that the understanding licenses" (2017, p. 56).

Presumably we do not want to rule out one as understanding a subject matter if one can't draw out all inferences and perform all actions that the understanding licenses. For example, we don't want to deny understanding to a chemist who knows how to draw the inferences and perform the actions that understanding licenses except in the case of some particular obscure element, about which the chemist has a mental block.

I suggest we might then refine Elgin's position in the following way: Understanding requires knowing how to draw all the central inferences and perform central actions that the understanding licenses-where this will be (something like) those inferences and actions such that it matters to whether you can draw many of the other inferences and perform other actions the understanding licenses. For example, even if the aforementioned chemist's understanding licenses her to draw inferences and perform certain actions about the obscure element, and she is for whatever reason unable to do so due to a mental block, this mental block doesn't prevent her from doing most or all of the other things (i.e., draw inferences, perform actions) her understanding licenses. But if the chemist failed to know how to do basic chemical 
reactions (e.g., how to combine hydrogen and nitrogen in order to produce ammonia gas) then this actually would prevent her from knowing how to do many of the things that understanding chemistry would license - and so (plausibly) failing to have this (central) ability might indicate she really does lack understanding of chemistry.

Thus, there is a possible application of the centrality constraint on factivity proposals that might naturally lend itself to being incorporated into Elgin's own nonfactivist account-viz., a principled way of unpacking the action component of understanding that Elgin explicitly opts for. At this point it is worth asking: is there a reason to positively prefer a thoroughly non-factivist proposal (supplemented with this action/inference component) to a moderately factive one, which embraces a centrality constraint? The answer would be 'yes' if we should accept Elgin's argument from the history of science. This point merits some sustained attention.

The general structure of Elgin's (e.g., ibid. 58-60) argument goes as follows: (1) there are various cases in the history of science where a theory's central claims were strictly false; and yet (2) the proponents of such theories had some understanding of the phenomena the theories purport to describe. (3) moderately factive views can't make sense of (1) and (2). Therefore (4) moderately factive views are mistaken.

A notable example Elgin offers concerns the Copernican theory of the cosmos, a central claim of which is the contention that the Earth travels around the sun in a circular orbit. Given that Copernicus's view was predicated on absolute space (and so doesn't account for the fact that the sun itself is not located at a fixed point), a central claim of the view is, strictly speaking, false (ibid. 60). But, as the idea goes, embracing the Copernican model comes with a tremendous intellectual gain; by embracing it one leaves the Ptolemaic geocentric model behind and has a significantly better understanding than before.

There are two salient ways a factivist has available to respond to such cases. One is to simply dismiss attributions of understanding here as 'honorific' (ibid. 59-60). Such a move is one Elgin considers and I think rightly dismisses. Granted, some cases where understanding is lacked are such that honorific attributions are felicitous; however, it's hardly clear that that's what's going on here, especially when the relevant intellectual gain is pointed out. Put another way, the burden would seem to be on the factivist to explain why this particular understanding attribution is merely honorific.

But there is a better strategy available to the factivist, one that involves a more fine-grained focus on the object of understanding in these cases. To begin, note that a moderately factive account implies that Copernicus did not understand the cosmos (or perhaps: the earth and sun in relation to the cosmos) in virtue of his false central belief. This is I think the right result. Though it hardly reflects poorly on Copernicus. It is widely thought in theoretical physics that approximately $70 \%$ of the universe is made of dark energy which itself is not understood. It is fair to say that no one understands the subject matter that is the cosmos. The factivist is not worse off for implying Copernicus does not.

What the above suggests is that if Copernicus-style cases are a problem for moderate factivity, then it must be because (despite a false central belief) understanding of something more specific than the cosmos simpliciter is present, and that this is so despite the presence of a false central belief. Once we think of the problem this 
way, though, it's much less clear that the factivist is in any trouble at all. Take, for instance, the subject matter that is: earth's relationship to the sun-setting aside the wider cosmos and the sun's position within it. Despite a false belief about the absolute location of the sun, Copernicus is able to reliably make predictions about this relationship that he was unable to make before. What this indicates, interestingly, is that a belief one way or the other about the sun's absolute location in the universe (viz., the point on which Copernicus was mistaken) is not central to understanding the subject matter that is the relationship between the sun and the earth.

But if that's right, then the moderate factivist, no less than the non-factivist, has the resources available for diagnosing such cases in a plausible way; and, more generally, we have reason to doubt that cases in the history of science are as troubling to a reasonably articulated moderative factivism as Elgin supposes.

\section{Norms of assertion}

I want to conclude by developing what I take to be a pleasing but unexplored consequence of a central part of Elgin's view. In particular, I want to show how Elgin's account of the grasping component of understanding in terms of know-how has the resources to resolve a standing issue in the contemporary literature on the epistemic norms governing assertion. ${ }^{11}$ I will close by detailing and expanding on what I take to be this benefit of her proposal.

The speech act of assertion is widely taken to be governed by some (to be specified) epistemic norm. For example, if you assert that $\mathrm{p}$, and then it turns out that you were guessing or had scant evidence for what you said, it looks as though your assertion is defective; it would be appropriate to criticise your assertion in such a circumstances. For example: "You shouldn't have told her the food is microwaveable-you haven't even looked at the label" or "You shouldn't have asserted that the client should strike a plea bargain on the basis of having watched a few crime dramas on television."

According to the knowledge account of assertion ${ }^{12}$ one's assertion that $\mathrm{p}$ is epistemically proper if and only if one knows that $\mathrm{p}$. On the necessity leg of this account (KNA-N), one's assertion that $\mathrm{p}$ is epistemically proper only if one knows $\mathrm{p}$, and on the sufficiency leg (KNA-S), one's assertion that $\mathrm{p}$ is epistemically proper if one knows that $\mathrm{p}$. Much of the contemporary criticism to the knowledge account has focused on KNA-N (and thus on whether knowledge is necessary for epistemically proper assertion, or whether what's necessary is merely justified belief). However, more recently, the sufficiency leg has received its own kind of challenge.

Defenders of the sufficiency leg of the knowledge account include DeRose (2002), Simion (2015), Hawthorne (2004) and Matt Benton (2014). If KNA-S is right, then whenever one knows what one asserts, then even if one might be

11 For a representative sample of essays engaged in this debate, see (eds.) Brown and Cappelen (2011).

12 For the seminal presentation of this view, see Williamson (1996). 
criticisable on non-epistemic (e.g., moral) grounds for making the assertion one did, the assertion is epistemically beyond reproach.

One case that has been controversial in the recent literature [especially between Benton (2016), Simion (2015), Lackey (2011, 2014) and Carter and Gordon (2011, 2017)] and which appears to raise trouble for KNA-S is the following:

DOCTOR: Matilda is an oncologist at a teaching hospital who has been diagnosing and treating various kinds of cancers for the past fifteen years. One of her patients, Derek, was recently referred to her office because he has been experiencing intense abdominal pain for a couple of weeks. After requesting an ultrasound and MRI, the results of the tests arrived on Matilda's day off; consequently, all of the relevant data were reviewed by Nancy, a competent medical student in oncology training at her hospital. Being able to confer for only a very brief period of time prior to Derek's appointment today, Nancy communicated to Matilda simply that her diagnosis is pancreatic cancer, without offering any of the details of the test results or the reasons underlying her conclusion. Shortly thereafter, Matilda had her appointment with Derek, where she truly asserts to him purely on the basis of Nancy's reliable testimony, "I am very sorry to tell you this, but you have pancreatic cancer. (Lackey 2008, pp. 3-4)

In the DOCTOR CASE, Matilda surely knows that Derek has cancer. After all, she heard this testimony from a known-to-be reliable source, and she lacks any undefeated defeaters. ${ }^{13}$ But, is Matilda properly epistemically positioned to flat out assert to Derek that he has pancreatic cancer? Consider, for one thing, that Derek would plausibly be displeased to learn that Matilda had diagnosed him without seeing his charts or examining him. Derek would reasonably be within his rights to expect Matilda to have a better grasp of his situation epistemically than she did.

In previous work (2011), I've suggested that what Matilda lacks here specifically is a kind of understanding, and that's why her assertion is (contra KNA-S) epistemically improper. More specifically, the suggestion was that certain epistemic roles a speaker may occupy carry with them expectations of expertise. (e.g., a doctor's diagnosis of a patient; an Olympic judge's evaluation of a skating performance; a risk-assessment professional's evaluation of the safety of a bridge, etc.)

In such cases, mere isolated (e.g., testimonial) knowledge is not enough, in the absence of grasping (in some suitably specified way) the subject matter in question. Thus, the suggestion is that understanding in at least some cases is the necessary epistemic credential to warrant assertion.

Elgin's account has the resources to offer a deeper diagnosis for why this would be so, and thus a more satisfying reason for rejecting KNA-S. According to Elgin (2017), understanding:

\footnotetext{
13 As the case is described, the hearer condition on testimonial knowledge is going to be satisfied not only on non-reductionist proposals but also on reductionist proposals, given that there are positive reasons to think that the speaker is reliable.
} 
involves knowing how to wield the commitments that bear on the topic-how to draw the inferences and perform the actions that the understanding licenses. That know-how is, in Rylean terms, a multitrack disposition-an ability and propensity to make certain inferences and eschew others, to perform certain actions and refrain from others, to engage in and endorse certain forms of higher-order evaluation and criticism and avoid and repudiate others (2017, p. 56, emphasis mine).

With Elgin's characterisation of these ability-relevant features of understanding in hand-along with some additional plausible premises-the following diagnosis of DOCTOR becomes available: In a social community, expertise is signalled by certain institutional roles, e.g., the institutional role of a medical doctor. When one speaks as an occupier of such a role, the hearer is warranted to expect that the speaker speaks with the kind of expertise that is associated with the role. Such expectations include the expectation that the speaker (qua occupying that role) be able not merely to state facts accurately, but to have a propensity to (as Elgin says) "make certain inferences, to perform certain actions and refrain from others, to engage in and endorse certain forms of evaluation and criticism and avoid and repudiate others." If we discovered that the speaker was unable to do these things on the topic at hand (e.g., Matilda in DOCTOR), then regardless of what facts speaker knows, that warranted expectation on the part of the hearer is not met, and the assertion is epistemically criticisable. If (per Elgin) understanding essentially involves knowing how to do such things, then (in DOCTOR) Matilda's assertion is criticisable precisely because she lacked understanding that Derek was warranted in expecting her to have.

In sketching out the above diagnosis, I hope to have shown how Elgin has the resources to help bolster the claim that, in certain cases, understanding rather than knowledge is what gives us the appropriate epistemic credentials to assert. If this is right, this shows a way that Elgin's account might take us further than others in diagnosing where proponents of the knowledge norm of assertion come up short.

\section{Conclusion}

The aim of this paper has been to provide a critical exploration of some of the key themes of one of the central chapters in Elgin's True Enough. In particular, I have examined the (1) the role of know-how, (2) the concept of endorsement in Elgin's account of understanding, (3) her critique of the factivity constraint on understanding, and (4) how we might use aspects of Elgin's framework to inform related debates about the epistemic norm or norms governing assertion. One topic I've not engaged with here - as it merits an extended separate discussionis Elgin's ingenuitive account of the role of exemplification in understanding, as a way of fleshing out the positive way how understanding can be a non-factive cognitive achievement. Even more, Elgin takes care to show how her view has rich implications for how we think about aesthetic understanding, including in the case of dance. The present focus, while setting aside these interesting features 
of the overall proposal, has hopefully shown how attention to Elgin's Chapter 3 reveals not only some ways to improve Elgin's own thinking about knowledge and understanding, but also some ways in which we might make progress when theorising about this relationship more generally. ${ }^{14}$

Open Access This article is distributed under the terms of the Creative Commons Attribution 4.0 International License (http://creativecommons.org/licenses/by/4.0/), which permits unrestricted use, distribution, and reproduction in any medium, provided you give appropriate credit to the original author(s) and the source, provide a link to the Creative Commons license, and indicate if changes were made.

\section{References}

Bengson, J., \& Moffett, M. (2011). Two conceptions of mind and action: Knowing how and the philosophical theory of intelligence. In J. Bengson \& M. Moffett (Eds.), Knowing how: Essays on knowledge, mind, and action (pp. 3-58). Oxford: Oxford University Press.

Benton, M. (2014). Knowledge norms. Internet Encyclopedia of Philosophy. ISSN 2161-0002.

Benton, M. (2016). Expert opinion and second-hand knowledge. Philosophy and Phenomenological Research, 92(2), 492-508.

Bradford, G. (2015). Achievement. Oxford: Oxford University Press.

Brown, J., \& Cappelen, H. (Eds.). (2011). Assertion: New philosophical essays. Chicago: Oxford University Press.

Carter, J. A., \& Gordon, E. C. (2011). Norms of assertion: The quantity and quality of epistemic support. Philosophia, 39(4), 615-635.

Carter, J. A., \& Gordon, E. C. (2017). Knowledge, assertion and intellectual humility. In J. A. Carter, J. Kallestrup, \& D. Pritchard (Eds.), Logos and episteme (special issue on intellectual humility), issue 4 (pp. 489-502).

Carter, J. A., \& Navarro, J. (2017). The defeasibility of knowledge-how. Philosophy and Phenomenological Research, 95(3), 662-685.

Carter, J. A., \& Pritchard, D. (2015). Knowledge-how and cognitive achievement. Philosophy and Phenomenological Research, 91(1), 181-199.

DeRose, K. (2002). Assertion, knowledge and context. Philosophical Review, 111(2), 167-203.

Elgin, C. (2017). True enough. Cambridge, MA: MIT Press.

Greco, J. (2010). Achieving knowledge: A virtue-theoretic account of epistemic normativity. Cambridge: Cambridge University Press.

Hawthorne, J. (2004). Knowledge and lotteries. Oxford: Oxford University Press.

Hills, A. (2009). Moral testimony and moral epistemology. Ethics, 120(2009), 94-127.

Kelp, C. (2015). Understanding phenomena. Synthese, 192(12), 3799-3816.

Kvanvig, Jonathan. (2003). The value of knowledge and the pursuit of understanding. Cambridge: Cambridge University Press.

Lackey, J. (2008). Learning from words. Oxford: Oxford University Press.

Lackey, J. (2011). Assertion and isolated second-hand knowledge. In J. Brown \& H. Cappelen (Eds.), Assertion: New philosophical essay (pp. 251-276). Oxford: Oxford University Press.

Lackey, J. (2014). Assertion and expertise. Philosophy and Phenomenological Research, 92(2), 509-517.

Lowenstein, D. (2017). Know-how as competence. A Rylean responsibilist account. Frankfurt: Verlag Vittorio Klostermann.

Pritchard, D. (2012). Anti-luck virtue epistemology. Journal of Philosophy, 109(3), 247-279.

\footnotetext{
14 Thanks to Catherine Elgin and the other speakers and participants at the University of Innsbruck's International "True Enough?" Book Symposium for their helpful feedback on an early version of this paper. I'm also grateful to J. Adam Carter for useful discussions on understanding and know-how, as well as to anonymous referees at Synthese for their thoughtful comments.
} 
Pritchard, D. (2016). Seeing it for oneself: Perceptual knowledge, understanding, and intellectual autonomy. Episteme, 13(1), 29-42.

Riggs, W. (2008). The value turn in epistemology. In V. Hendricks (Ed.), New waves in epistemology (pp. 300-323). Basingstoke: Palgrave Macmillan.

Riggs, W. (2009). Understanding, knowledge, and the meno requirement. In D. Pritchard, A. Millar, \& A. Haddock (Eds.), Epistemic value. Oxford: Oxford University Press.

Ryle, G. (1945). Knowing how and knowing that. Proceedings of the Aristotelian Society, 46, 1-16.

Ryle, G. (1949). The concept of mind. New York: Routledge.

Simion, M. (2015). Assertion: Knowledge is enough. Synthese, 193(10), 3041-3056.

Sliwa, P. (2015). IV-Understanding and knowing. Proceedings of the Aristotelian Society, 115(1), 57-74.

Sosa, E. (2010). How competence matters in epistemology. Philosophical Perspectives, 24(1), 465-475.

Sosa, E. (2015). Judgment and agency. Oxford: Oxford University Press.

Sosa, E. (2017). Epistemology. Princeton: Princeton University Press.

Stanley, J. (2011). Know how. Oxford: Oxford University Press.

Stanley, J., \& Williamson, T. (2001). Knowing how. The Journal of Philosophy, 98(8), 414-444.

Williamson, T. (1996). Knowing and asserting. The Philosophical Review, 105(4), 489-523.

Publisher's Note Springer Nature remains neutral with regard to jurisdictional claims in published maps and institutional affiliations. 